\title{
Part V. Acoustic and Seismic Waves
}

\section{By Yukio KAWABATA}

(Japan Meteorological Agency)

At about $15^{h}$ GMT on August 12, 1958, we observed small acoustic wave oscillations all

\begin{tabular}{|c|c|c|c|c|c|c|c|}
\hline Place & Latitude & Longitude & $\underset{(\mathrm{m})}{\mathrm{h}}$ & $\begin{array}{c}\text { Beginning } \\
\text { of the wave } \\
\text { (GMT) }\end{array}$ & $\underset{(\mathrm{mb})}{\text { Amplitude }}$ & $\begin{array}{c}\text { Period } \\
(\mathrm{min})\end{array}$ & $\underset{(\min )}{\text { Duration }}$ \\
\hline Kushiro & $\mathrm{N} 42^{\circ} 59^{\prime}$ & E $144^{\circ} 24^{\prime}$ & 34 & $15^{\mathrm{h}} 01^{\mathrm{m}}$ & 0.2 & 5 & 40 \\
\hline Akita & 3943 & 14006 & 10 & $15 \quad 15$ & 0.1 & 4 & 25 \\
\hline Tokyo & 3541 & 13946 & 6 & $15 \quad 12$ & 0.1 & 4 & 30 \\
\hline Wajima & 3723 & 13654 & 7 & $15 \quad 25$ & 0.1 & & 20 \\
\hline Muroto-zaki & 3315 & 13411 & 186 & $15 \quad 35$ & 0.1 & & 53 \\
\hline Kagoshima & 3134 & 13033 & 5 & 1553 & 0.1 & 4 & 11 \\
\hline Osaka & 3439 & 13532 & 8 & $15 \quad 34$ & 0.1 & & 30 \\
\hline Okayama & 3441 & 13355 & 5 & $16 \quad 12$ & 0.1 & 3 & 50 \\
\hline Matsuyama & 3350 & 13247 & 34 & $15 \quad 43$ & 0.1 & & 15 \\
\hline Uwajima & 3314 & 13233 & 43 & $15 \quad 53$ & 0.0 & & 9 \\
\hline Yokohama & 3526 & 13939 & 38 & $15 \quad 16$ & & & \\
\hline
\end{tabular}

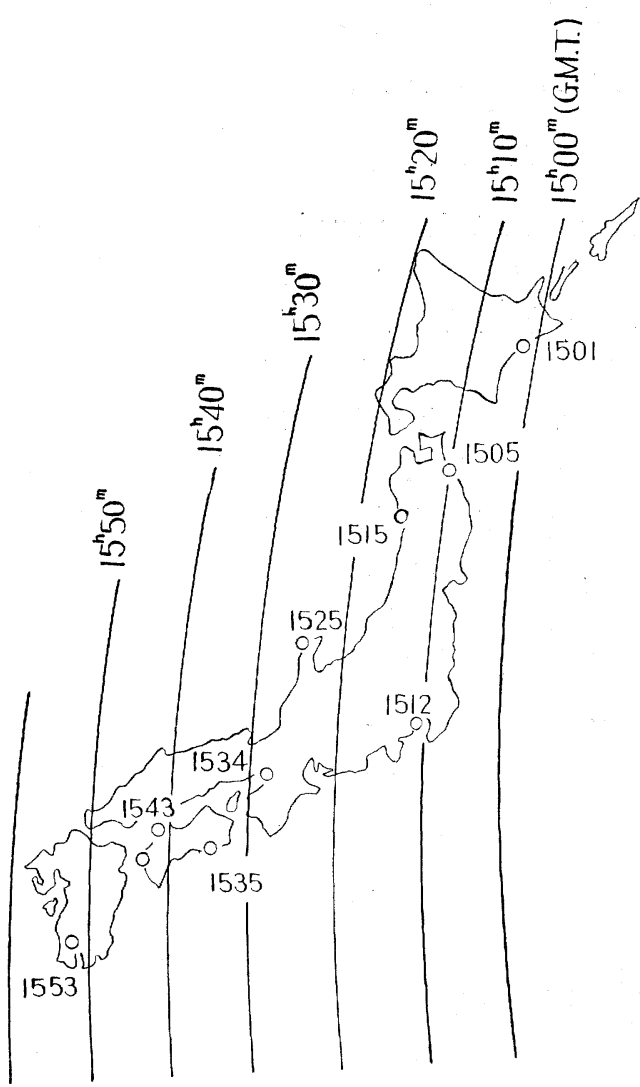

Fig. 19. Distribution of acoustic wave observatories in Japan and the observed time of starting of oscillations. over Japan which were not considered to be of natural origin. The period of beginning of the waves was found to be about 4 minutes, the maximum amplitude was almost $0.1 \mathrm{mb}$., and the duration of the wave oscillations was about 10-50 minutes. (Refer to Fig. 19.) The observational data are shown in the above table.

Drawing the propagation of this wave on a map, as seen in Fig. 20, we can find that the origin of this acoustic wave lies almost in an ESE direction from Japan. The distance is so great and the curvature of the wave front is so flat that we can not determine its origin exactly, but it seems that the distance may

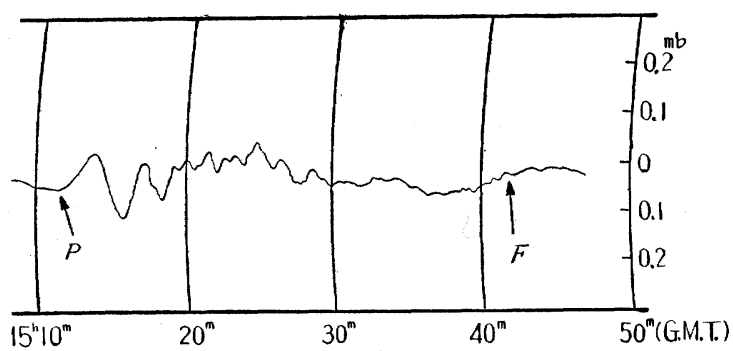

Fig. 20. Record of small acoustic wave oscillations at Tokyo on Aug. 12, 1958. 

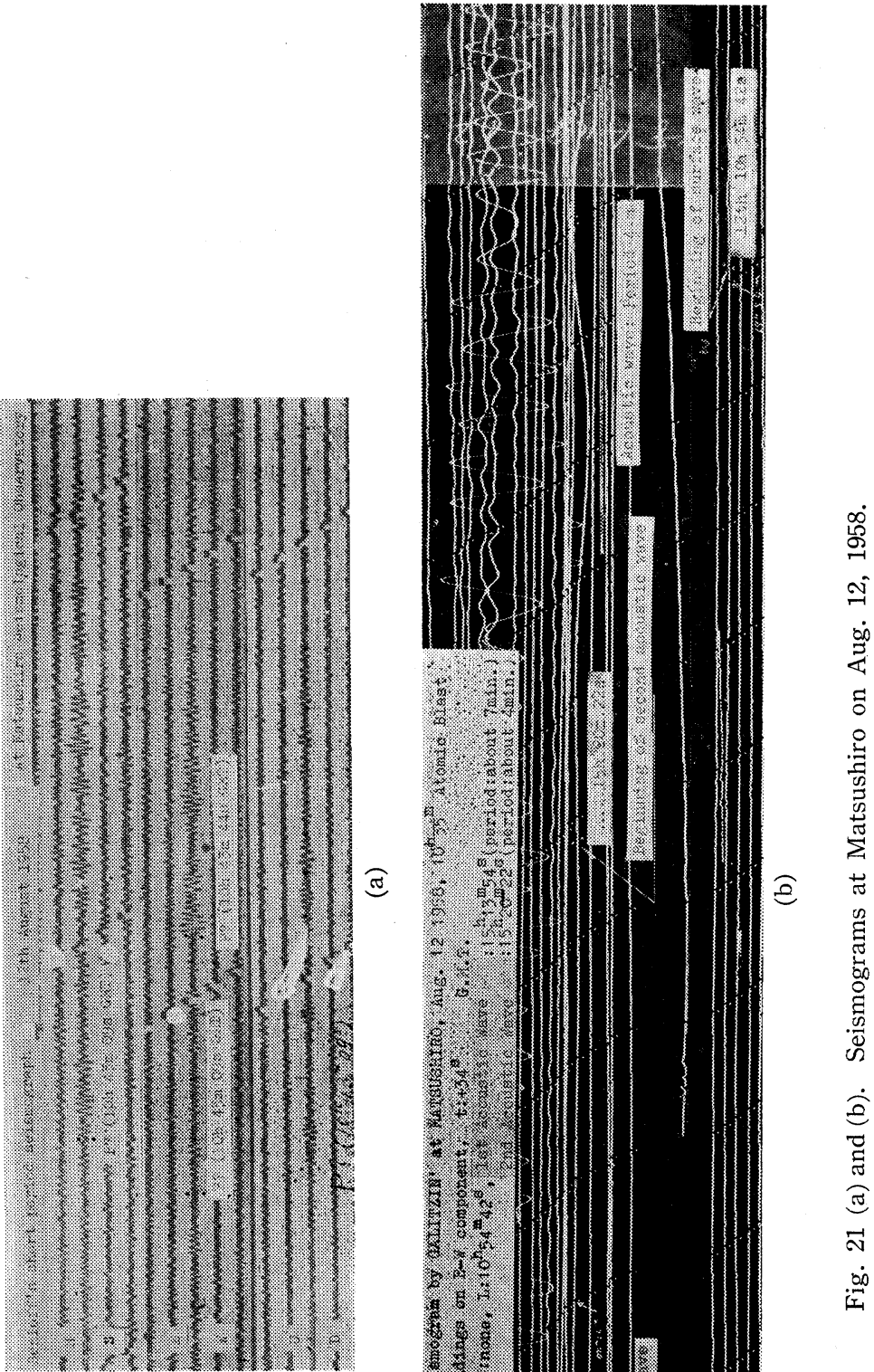
be almost $5500 \mathrm{~km}$ from Tokyo as far away as Johnston Istand in the Pacific.

At the same time we observed at Matsushiro Seismic Observatory the seismic wave due to this nuclear test. The P-wave (longitudi nal wave) was observed at $10^{h}$ $43^{m} 44^{s}$ and the L-wave (Surface wave) at about $10^{h} 55^{m}$. (Refer to Fig. 21 (a)). From these data, the time of occurrence was determined to be $10^{h} 34^{m}$ GMT.

It should be noticed that the acoustic waves were observed on the seismograms, too. (Refer to Fig. 21 (b)).

\section{Conclusion}

All the phenomena associated with the nuclear explosion as explained above are arranged according to the time of their appearance as represented in Figs. 22 (a) and (b).

\begin{tabular}{|c|c|}
\hline Aurora (Apia) & \\
\hline $\begin{array}{c}\text { Geomagnetism (Honolulu) } \\
\text { (Apia) }\end{array}$ & $\begin{array}{c}\text { Unknown } \\
\text { Unknown }\end{array}$ \\
\hline Atmospherics (Toyokawo) \\
(Hiraiso)
\end{tabular}

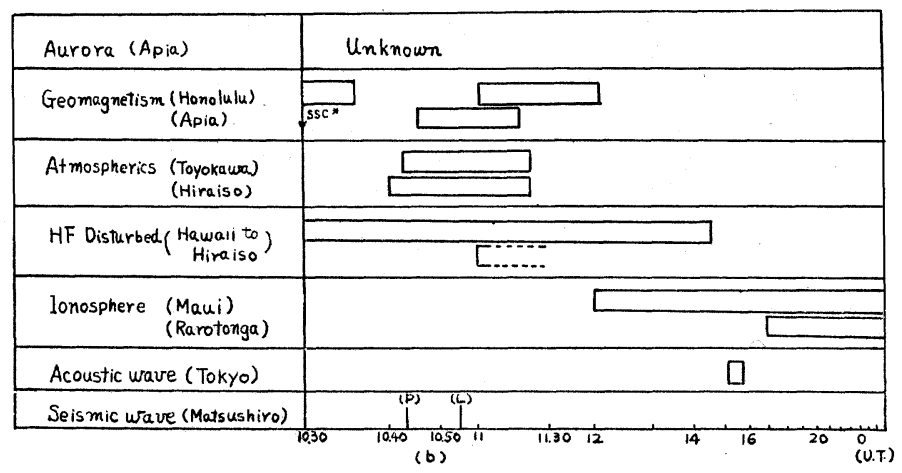

Fig. 22. Duration of main effects associated with the nuclear explosion on (a) Aug. 1, 1958, (b) Aug. 12, 1958.

Some differences will be seen between the phenomena on August 1 and 12. Especially it must be noticed that no micro-pulsation of the atmospheric pressure on August 1 was observed in Japan, whereas no aurora was reported at Apia on August 12.

It will be supposedly due to different heights and different conditions of each nuclear explosion. However, it will very likely become important keys to the solution of the phenomena.

At the present stage of study, the amount of data and information is not enough to account for them. Even from the data above mentioned, however, the following conclusion may be dẹived: 
The mechanisms of excitation of various phenomena seem to be complicated and correlated with each other. Of course, each phenomenon has its own mechanism which has not necessarily a single process. Each process will give rise to the disturbances of associated phenomena. Accordingly, it is wiser to distinguish the processes one by one, but it will be a difficult task to tackle.

Fig. 22 will give a general view of all the phenomena, from which we can have three stages of the period. The first period has the duration of several minutes immediately after the time of explosion, the second period of several decades of minutes following, and the third period of more than ten hours subsequent to the end of the second period.

It is supposed that the first period will comprise the direct process such as radiation, hydromagnetic wave and high-speed neutral and charged particles, the second period rather propagational process with lower speed than the direct process, such as shock wave, and the third period the conservative process of the active nuclear cloud drifting or suspending in high altitudes.

Strict interpretation, anyhow, should be left for the future when the data and information available reach an amount sufficient for analysis.

We hope the studies on the geophysical effects associated with high-altitude explosions whould be coordinated as widely as possible in order to account for the artificial ionospheric and geomagnetic disturbances as well as the artificial aurora. 